ARTIGO

\title{
Uma análise crítica do acordo de associação estratégica entre a União Européia e a América Latina e o Caribe - A Cúpula de Viena
}

\author{
A critical analysis of the "strategic association" between the \\ European Union and the Latin America and the Caribbean \\ - The Europe - LAC Vienna Summit
}

FRANKLIN TREIN*

FLÁVIA GUERRA CAVALCANTI**

Rev. Bras. Polit. Int. 50 (1): 66-85 [2007]

\section{Introdução}

Nos meses que precederam a realização da Cúpula de Viena entre União Européia, América Latina e Caribe, realizada em 11 e 12 de maio de 2006, pôdese perceber uma grande expectativa em relação a este encontro. Esperava-se que Viena significasse uma mudança qualitativa em relação às cúpulas anteriores: a do Rio (1999), a de Madri (2002) e a de Guadalajara (2004). A Associação Estratégica proposta no primeiro encontro, em 1999, já era algo mais profundo do que os tradicionais laços comerciais. Propunha-se a promover a aproximação entre as Sociedades Civis em todas as áreas passíveis de serem integradas. No entanto, desde então, as partes envolvidas nas negociações vêm enfrentando dificuldades para uma efetiva implementação daquele projeto na sua formulação original.

Deste modo, Viena não poderia ser apenas mais uma cúpula. "Queremos reforçar nosso entendimento comum e a associação existente entre as duas regiōes para criar diálogos e oportunidades novas", declarou a comissária das Relações Exteriores da União Européia, Dra. Benita Ferrero-Waldner. Ou seja, a Cúpula deveria não só consolidar os avanços alcançados, senão que dar um passo além na Associação Estratégica, criando novos mecanismos de aproximação.

Os desafios de Viena tornavam-se ainda maiores quando se considerava o contexto histórico regional e internacional, marcado pela aceleração da competição econômica globalizada, pelo unilateralismo norte-americano e por

\footnotetext{
* Professor Associado do Programa de Pós-Graduação em Ciência Política e Coordenador do Programa de Estudos Europeus da Universidade Federal do Rio de Janeiro - UFRJ (trein@ifcs.ufrj.br)

** Jornalista, mestre em Ciência Política pela Universidade Federal do Rio de Janeiro - UFRJ e Pesquisadora Associada do Programa de Estudos Europeus da mesma universidade.
} 
questionamentos dos processos de integração tanto na União Européia quanto na América Latina e no Caribe.

Diante do bom desempenho econômico americano e chinês, de um lado, e do fraco crescimento europeu, de outro, a União Européia entende que precisa fortalecer suas parcerias econômicas internacionais. Assim, uma associação com a América Latina e o Caribe é sempre lembrada tendo em conta não só as potencialidades da região, mas ainda as relações históricas, a proximidade cultural e o compartilhamento de valores sociais e políticos comuns. Por outro lado, nos discursos preparatórios da reunião de Viena, a Europa parecia pretender fazer da parceria política com a América Latina e o Caribe uma afirmação de sua concepção de multilateralismo na cena internacional, se contrapondo desta forma, frontalmente, à posição unilateralista da política externa americana.

A América Latina, por sua vez, diversamente, está num momento de relativa estabilidade. Valendo-se das condições de normalidade política, apesar das dificuldades, retoma iniciativas no sentido de sua integração. Na medida em que, muitas vezes, o que foi interpretado como "crise na América Latina" não passa de efeitos colaterais de um aprofundamento da integração, o desafio da União Européia, portanto, era e é o de se aproximar de uma região em movimento e transformações constantes. A Cúpula de Viena para a União Européia significou, outra vez, o desafio de sempre: concretizar uma aliança consistente, apoiada no princípio de respeito mútuo das diferenças com uma região com a qual, por desconhecê-la em seus processos mais complexos e por condicionantes internos da própria UE, ela tem dificuldades históricas de aproximação.

Dentro deste contexto, a reunião em Viena deveria propor um modo de fazer da Associação Estratégica um tipo de associação entre as duas regiōes, possível de ser realizado, enquanto os respectivos processos de integração ainda não atingiram sua maturidade. Acreditava-se ainda que Viena poderia oferecer uma alternativa institucional para os mecanismos de reuniões de cúpulas como, por exemplo, a organização de encontros anuais, em nível ministerial, para acompanhar e implementar os pontos acordados nas reuniōes de chefes de governo e de Estado. Ou ainda, deveria implementar a criação de um secretariado permanente para as relaçōes União Européia, América Latina e Caribe nos moldes da Secretaria-Geral Ibero-Americana, criada pela XV Conferência Ibero-Americana em 2005, em Salamanca.

Neste ensaio, buscaremos apresentar um panorama das relações entre a União Européia, a América Latina e o Caribe, desde os anos 70, e um histórico das reuniões de cúpulas que acompanharam a aproximação entre as partes envolvidas.

\section{Histórico das relações entre a União Européia, a América Latina e o Caribe}

Embora marcada por avanços e recuos na segunda metade do século XX, a relação entre a União Européia e a América Latina e o Caribe apresenta um 
movimento contínuo no sentido da intensificação e da aproximação entre as partes. Passou-se de uma situação de desconhecimento recíproco, nos anos 50, principalmente por parte da Europa, a uma fase de aproximação gradativa, a partir dos anos 70. Para efeito de análise, essas relações podem ser divididas em quatro fases, às quais correspondem quatro tipos ou "geraçôes" de acordos, cada um com características e alcances muito distintos, que mostram o estado da arte das mesmas em cada etapa.

Entre 1957 e 1971, as relações entre as regiões ainda eram bastante restritas, pois a América Latina e o Caribe ocupavam uma posição secundária na pirâmide de prioridades da Comunidade Econômica Européia (CEE). Nessa fase, a CEE estava envolvida com a construção de sua própria integração e com o estabelecimento de uma parceria privilegiada com os países africanos em processo de descolonização. Além disso, naquele momento a Europa ainda percebia a América Latina e o Caribe como uma área de influência norte-americana, o que a desestimulava a procurar aumentar sua presença na região.

A partir do fim do sistema de Bretton Woods, em 1971, e da crise do petróleo, em 1973, os países da Comunidade enfrentam recessão, inflação e desemprego. A Europa se deu conta, então, de sua vulnerabilidade externa e, em conseqüência, da necessidade de se aproximar de regiōes periféricas, como forma de ampliar suas oportunidades de investimentos e de acesso a mercados para seus produtos, além de assegurar fontes alternativas de matérias-primas.

Já naquela década começou a mudar, ainda que lentamente, a percepção européia sobre a América Latina, que passava a ser vista pelos europeus como um continente estratégico. Surgiram então os acordos de primeira geração, que visavam melhorar as posições comerciais européias na América Latina. Tais acordos apresentavam três características. Primeiro, eram assinados com países latinoamericanos de grande potencial econômico naquele momento; segundo, eram bilaterais, sempre entre Bruxelas e um país da América Latina, sem considerar qualquer eventual estrutura regional de integração do lado latino-americano; e, terceiro, estavam baseados no artigo 113 do Tratado da Comunidade Econômica Européia, segundo o qual as relaçōes ali contempladas teriam um caráter estritamente comercial, não-preferencial.

Esse tipo de acordo exigia a adoção da cláusula de nação mais favorecida do Gatt, conforme a qual "os membros estão obrigados a conceder aos produtos dos demais membros um tratamento não menos favorável do que aquele que dispensam aos produtos de qualquer outro país". Seu caráter não-preferencial, portanto, não garantia aos países latino-americanos e caribenhos qualquer vantagem a mais - ou melhores preferências - do que aquelas já concedidas a outros países no âmbito do Acordo Geral de Tarifas e Comércio (Gatt). A Europa podia, assim, manter sua política protecionista em relação à América Latina e ao Caribe, limitando por outros meios o acesso dos produtos dos países latinoamericanos e caribenhos ao mercado comunitário. 
São deste teor os acordos comerciais bilaterais assinados pela Comunidade Européia com Argentina (1971), Uruguai (1973) e Brasil (1974). Em 1975, a Comunidade Européia assinou um acordo de cooperação com o México, o qual chegou a ser apresentado como uma novidade porque continha uma "cláusula evolutiva” segundo a qual as partes deveriam se esforçar para ampliar e aprofundar a cooperação. Na prática, no entanto, a cláusula não foi aplicada e o acordo acabou tendo os mesmos efeitos dos documentos anteriores, de primeira geração.

O principal êxito daquela primeira geração de acordos foi o estabelecimento de um diálogo entre a Comunidade Econômica Européia e a América Latina e o Caribe através de dois órgãos: um grupo permanente de consulta, composto por embaixadores latino-americanos sediados em Bruxelas - o GRULA - e uma sede da Delegação da Comissão Européia para a América Latina, em Caracas.

As relações entre a União Européia e a América Latina só avançaram para um novo patamar no início dos anos 80 , quando uma nova conjuntura internacional, conseqüência das sucessivas crises do petróleo e do início da era Thatcher/Reagan, mostrou a limitação dos intercâmbios meramente comerciais entre os blocos. O recrudescimento da luta entre os partidários de Somoza e os sandinistas na Nicarágua, que ameaçou desestabilizar a América Central, levou a Europa a reforçar sua presença na região com o objetivo de intermediar uma solução negociada, o que estava fora do alcance dos Estados Unidos por seu envolvimento clandestino na escalada do conflito. A crise da dívida externa latino-americana (1981-1982) teve implicações não só econômicas, mas também políticas para a relação entre a Europa e a América Latina. Já a Guerra das Malvinas, que envolveu a Argentina e o Reino Unido, pôs em evidência a falta de um diálogo político efetivo entre aqueles dois países, o que era só mais uma expressão da falta de diálogo entre as duas regiōes. Nesse cenário, contudo, o fim das ditaduras militares e a gradual redemocratização dos países do Cone Sul, nos anos 80 , contribuíram para o início do que os países latino-americanos chamaram de um "diálogo renovado" com a Comunidade Européia.

A entrada em 1985 da Espanha e de Portugal na Comunidade Européia, países com fortes laços históricos e culturais com latino-americanos e caribenhos, foi um fator importante, direta e indiretamente, no sentido de acelerar o processo de aproximação entre as duas regiōes.

Ainda na fase de negociações de suas respectivas adesões à CE, os países ibéricos começaram a influenciar as instituições comunitárias para que estas se aproximassem da América Latina e do Caribe. Mas o ingresso de Portugal e Espanha na Comunidade Européia produziu ainda um outro efeito sobre as relações União Européia, América Latina e Caribe. A inclusão de países do Sul da Europa com grau de desenvolvimento inferior ao dos países fundadores levou a uma reformulação das relaçóes exteriores da CE e, particularmente, de sua política de "cooperação para o desenvolvimento". 
A insistência de Espanha e Portugal em aproximar a Europa da América Latina chamou a atenção para o potencial da dimensão cultural das relações como base para uma aproximação mais substantiva entre as regiōes. Da mesma forma, a solidariedade com os países mais pobres da Comunidade trouxe a percepção de que as relações externas da CE não deveriam ser motivadas tão somente pela expectativa de retornos econômicos de curto prazo.

De modo geral, a ampliação do processo de integração, com a participação de novos membros, não significou um maior fechamento da Europa para com o restante da Comunidade Internacional. No caso da adesão dos países ibéricos à Comunidade Européia, a ampliação provocou mudanças positivas nas relações biregionais com a América Latina e o Caribe. É verdade que muito mais limitadas do que as expectativas iniciais dos latino-americanos e caribenhos.

Em meio a esse novo contexto, os acordos de segunda geração foram além dos interesses meramente comerciais e se estenderam, pelo menos formalmente, também ao campo político. Assim, em 1980, a Comunidade Européia assinou um acordo de cooperação com o Brasil, que substituiu o acordo comercial firmado em 1974. Em 1983 o acordo da CE foi com o Grupo Andino. No ano seguinte, 1984, a CE inicia o "Diálogo de San José" com os países da América Central, numa tentativa de diálogo político, que acabou por romper com o monopólio até então exercido pelos Estados Unidos e que resultou num acordo de cooperação em 1985.

$\mathrm{O}$ início dos anos 80 ainda estava marcado pela postura protecionista, que se seguiu à crise do petróleo da década de 70 e resultou no fracasso da Rodada de Tóquio do Gatt (1973/1979). A política comercial da União Européia para a América Latina e o Caribe continuou sendo não-preferencial e os acordos de cooperação econômica e para o desenvolvimento seguiram apenas como "acordosmarco", ou seja, declarações de intençōes em que as partes se comprometem a aprofundar a cooperação em negociações posteriores.

Outra característica desses acordos de segunda geração é que eles romperam com a política, predominantemente bilateral, dos anos 70 e anteciparam uma política sub-regional para a América Latina e o Caribe, que iria se impor a partir dos anos 90. Exemplos neste sentido foram os casos da cooperação com o Grupo Andino e com a América Central, que, além da política comercial e da cooperação econômica, incluíam uma perspectiva de "cooperação para o desenvolvimento".

Nos anos 80, os acordos de cooperação entre a Comunidade Européia e a América Latina adotaram o modelo dos já existentes, nessa época, entre a Europa e os países em desenvolvimento da Ásia, tais como a Índia e os Estados-membros da Associação de Nações do Sudeste Asiático (ASEAN).

É interessante observar que até então, apesar das afinidades culturais, a Ásia havia ocupado uma posição nitidamente mais importante do que a América Latina na ordem de prioridades da Europa. O que os acordos de segunda geração 
fizeram foi aproximar, no quadro da CE, o status dos países ou de sub-regióes na América Latina e no Caribe ao dos países asiáticos.

As discussōes sobre os acordos de terceira geração tiveram início a partir do final dos anos 80 e começo dos anos 90. Aconteceram num contexto de liberalização comercial e de grandes transformaçōes políticas, técnico-científicas, sociais e culturais decorrentes da aceleração do processo de globalização. Com o fim da Guerra Fria, de um lado, assistimos à constituição de uma unipolaridade representada pelos Estados Unidos, e de outro, a uma proliferação de blocos regionais que, de alguma forma e sob circunstâncias não realizadas, poderiam ter resistido à hegemonia americana e forçado a evolução do cenário internacional na direção de um sistema multilateral. A percepção, que começou a surgir timidamente na Comunidade Européia dos anos 70, de que a América Latina era um Continente estratégico para seus interesses econômicos e políticos se tornou, aos poucos, mais consistente a partir daquele momento.

Em suma, tivemos nos anos 90 - e temos ainda hoje-um sistema internacional em movimento, cuja configuração mais estável dependerá das políticas adotadas por todos os atores, apesar do peso da hegemonia norte-americana nos processos de tomada de decisões nas relaçõos internacionais.

A América Latina intensificou seus processos de integração intra-regional com a criação do Mercosul em 1991, adotando a perspectiva de um "regionalismo aberto", segundo o qual zonas de livre-comércio e unióes aduaneiras são, necessariamente, promotoras do livre-comércio e possibilitam aos países que delas participam uma maior inserção nos mercados mundiais.

A Europa, por sua vez, muito antes, desde meados dos anos 80 , já vinha estudando medidas para relançar seu projeto de integração. $O$ persistente pessimismo europeu quanto ao futuro do processo de integração levou a Comissão Européia a encomendar um estudo sobre os custos da não-integração, o qual ficou conhecido como Relatório Cecchini. Naquele relatório, demonstrou-se que a Europa não tinha alternativas à integração que contemplasse sua opção de desenvolvimento, iniciada ao término da Segunda Guerra.

Desta forma, em 1986, o Ato Único Europeu estabeleceu que as questões de Política Comercial passavam a ser decididas não mais por unanimidade, mas por maioria qualificada. Era um modo de dar mais agilidade às decisões. Esse Ato decidiu ainda sobre as condiçōes necessárias ao estabelecimento de um mercado interno, até 1992, e sobre as bases de negociação da ainda "Comunidade Européia" com outros blocos.

Apesar dos avanços obtidos, isto não foi suficiente para superar a crise. Só um esforço extraordinário - como o que conduziu até à assinatura do Tratado de Maastricht, em 1992, transformando a "Comunidade Européia" na União Européia, o que significa dizer, estabelecendo novas bases para sua ampliação e aprofundamento - foi capaz de renovar efetivamente a dinâmica da integração comunitária. 
Os acordos de terceira geração refletiram esse momento de relançamento dos processos de integração e de liberalização comercial. Seus princípios estão no documento "Novas Orientações para a Cooperação com a América Latina e a Ásia na década de 90". Ali a União Européia manteve duas linhas de ação: ajuda ao desenvolvimento nos países mais pobres e "cooperação avançada" nos países em desenvolvimento, que vai além da cooperação assistencialista e visa a melhorar a eficácia dos sistemas produtivos.

Ao contrário dos acordos de segunda geração, os dos anos 90 incluíram uma "cláusula democrática" que condicionava os programas de cooperação à vigência da democracia. O compromisso democrático foi incorporado pela primeira vez no acordo-marco de cooperação comercial e econômica assinado entre a União Européia e a Argentina. Posteriormente, foi estendido aos demais acordos de terceira geração, ou seja, com o Chile (1990), Uruguai (1991), Paraguai e Brasil (1992) e América Central e Grupo Andino (1993). O acordo entre a UE e o México, em 1991, foi o único que não contemplou esta cláusula. Uma novidade, no entanto, foi a incorporação de uma "cláusula evolutiva", que obrigava ambas as partes a ampliarem as áreas de cooperação e aprofundarem a cooperação nas já existentes. Esta exigência já constava no acordo de primeira geração entre a UE e o México, de 1975, mas havia mostrado um alcance limitado. Na prática, os acordos-marco de terceira geração, e mesmo os de quarta, continuaram apresentando problemas para evoluir em direção a uma associação reforçada.

Apesar dos avanços, a relação da União Européia com a América Latina e o Caribe continuava em posição secundária na pirâmide de preferências européia. Já nessa época começou a surgir o desejo da América Latina de uma aproximação com a UE, que superasse os tipos de acordo feitos até então, isto é, os nãopreferenciais, seguidos de declaração de intenções e de cooperação avançada, mas que, de fato, pouco ou nada mudavam..

A partir de 1994, iniciam-se os acordos de quarta geração entre a União Européia e a América Latina. O êxito das negociaçóes multilaterais da Rodada Uruguai do Gatt, a criação da OMC, o desenvolvimento da Política Exterior e de Segurança Comum (PESC), instituída por Maastricht em 1992, a assinatura do Tratado de Livre-Comércio da América do Norte (NAFTA), o otimismo em relação ao Mercosul e a proliferação de acordos multilaterais e bilaterais mostram um reforço daquelas dinâmicas internacionais iniciadas no fim dos anos 80 .

O diálogo político e a cooperação para o desenvolvimento, que tinham começado a ganhar espaço nos acordos de segunda geração dos anos 80 , também estiveram presentes nos acordos de quarta geração. Na prática, porém, foram abandonados em favor de uma política preocupada apenas com os aspectos econômicos das relaçôes bi-regionais. A América Latina foi reposicionada na escala de preferências da União Européia, mas tão-só no que diz respeito às relações econômicas. Seguiram este espírito os acordos-marco da UE com Mercosul (1995), Chile (1996) e México ( 1997). 
Em outubro de 1995 a Comissão Européia definiu novas orientações para a cooperação UE-América Latina. No documento "União Européia-América Latina. Atualidade e perspectivas do fortalecimento da associação (1996-2000)", foi proposta pela primeira vez uma política de cooperação exclusiva para a América Latina, separada daquela da Ásia.

Em 15 de dezembro de 1995, foi assinado, em Madri, o Acordo Marco Inter-regional de Cooperação entre a União Européia e o Mercosul, que previa a criação de uma Área de Livre-Comércio entre os dois blocos em 10 anos e estabelecia a disposição das partes de exercitar um efetivo diálogo político. Este acordo representa um momento histórico, ele é o primeiro Tratado entre dois blocos regionais em processo de constituição de um mercado comum e um dos poucos de caráter verdadeiramente bi-regional. Além disso, as relações entre o Mercosul e a UE são as mais importantes do bloco América Latina-UE.

As negociações amplas começaram em 2000 e as discussões sobre reduções tarifárias, em julho de 2001. No início, a União Européia se recusou completamente a incluir o setor agrícola nas ofertas. Em 2003, os europeus mudaram essa posição, mas passaram a exigir, em contrapartida, uma maior abertura no setor de serviços e de compras governamentais, o que então foi rejeitado pelo Brasil. $\mathrm{Na}$ realidade, as reuniões que se seguiram ao Acordo-Marco de 1995 parecem ter esquecido, quase que totalmente, a dimensão política, reduzindo as negociações à busca de um entendimento que contemplasse somente os interesses econômicos. $\mathrm{O}$ resultado é que, até hoje, se avançou muito pouco. Os 10 anos previstos, na data de assinatura em Madri, para a realização de uma expressiva integração biregional entre o Mercosul e a União Européia já se esgotaram e as divergências permanecem, o diálogo político ficou sem espaço para o seu desenvolvimento.

Nessas três décadas nota-se que o método da União Européia para aproximação com a América Latina foi só o "Acordo-Marco", na verdade, um acordo que apenas define os princípios que deverão presidir uma futura negociação entre as partes. $\mathrm{O}$ único país que assinou um Acordo-Marco e conseguiu progredir em sua aproximação com a União Européia foi o México. Mas isto só ocorreu porque, paralelamente ao Acordo-Marco, o México assinou um outro acordo, que garantia a criação imediata de uma zona de livre-comércio com a UE, nos moldes da negociação do NAFTA.

Nota-se que todos os acordos dessa fase, tanto os chamados de AcordosMarco quanto acordos de criação imediata de uma zona de livre-comércio, estão restritos aos aspectos econômicos das relações bi-regionais. As dimensões política, social e cultural da integração só deverão ser contempladas mais tarde, na proposta de Associação Estratégica do século XXI.

\section{Histórico das Cúpulas União Européia-América Latina-Caribe}

As quatro gerações de acordos entre a União Européia e a América Latina e o Caribe prepararam gradativamente as condiçóes para a ambiciosa proposta 
de uma Associação ou Parceria Estratégica entre as duas regiōes, que surgiu pela primeira vez na Cúpula do Rio, em junho de 1999. Mais do que uma cooperação econômica ou política, o conceito de Associação Estratégica prevê uma integração nos aspectos sociais e culturais.

O diálogo político incipiente dos anos 80 não avançou na década seguinte, dominada por uma concepção meramente econômica da integração. A limitação das relações UE-América Latina-Caribe nas três décadas anteriores, apesar de algumas melhorias, mostrou claramente que o diálogo político por si só, sem o lastro cultural e social, não era suficiente para fazer avançar a relação bi-regional. A Cúpula do Rio, em 1999, teve, portanto, um caráter fundacional na medida em que representou uma ruptura nas relações União Européia-América LatinaCaribe. Ela não só tentou recuperar a perspectiva política, esquecida nos anos 90 , mas ainda acrescentou a esta os aspectos sociais e culturais.

A Cúpula do Rio significou um momento de tomada de consciência de que havia falhado a estratégia de compartimentalizar a realidade e integrar suas diversas dimensões separadamente e em momentos sucessivos - primeiro a econômica, depois a política e, por fim, a sócio-cultural. A “Associação Estratégica” propõe uma integração simultânea em todas as áreas.

A primeira Reunião de Cúpula, a do Rio de Janeiro, ocorreu num ambiente de otimismo sustentado por um ciclo de crescimento econômico mundial, estabilidade no Oriente Médio e um interesse particular da França e da Alemanha em expandir seus mercados e influência na América Latina. Adotou-se uma agenda ampliada com 55 prioridades, divididas em três âmbitos de ação: promoção de uma ordem internacional respaldada pelos princípios do direito internacional, com o objetivo de criar sociedades mais justas e eqüitativas; impulsão da integração regional através de acordos de associação, incluindo zonas de livre-comércio; e ainda ampliação e fortalecimento da cooperação em matéria de desenvolvimento, educação, cultura, ciência e tecnologia.

Nessa ocasião, foi estabelecido o Grupo Bi-regional de Altos Funcionários, que em novembro de 1999, ao se reunir pela primeira vez, em Tuusula, Finlândia, resumiu em 11 pontos as prioridades de ação estabelecidas no Rio de Janeiro. Os principais foram: a atuação conjunta em fóruns internacionais; a promoção dos direitos humanos e o combate à discriminação por raça e gênero; a cooperação em matéria de meio ambiente e desastres naturais; a implementação do "Plano Global de Ação contra Drogas"; o fomento da estabilidade financeira global e cooperação para fortalecer os sistemas financeiros nacionais; o fomento da cooperação empresarial e apoio à cooperação bi-regional em matéria de educação, herança cultural, sociedade da informação e integração regional.

Ao contrário dos países asiáticos, a UE sabe que, no caso da América Latina, há um substrato cultural comum a partir do qual ela pode construir uma Associação Estratégica. Contudo, o compartilhamento de valores semelhantes não significa 
uma unificação cultural. Na Declaração do Rio de Janeiro, está garantido o direito individual de manutenção da identidade cultural e lingüística assim como os direitos das populaçōes indígenas e a cooperação para a recuperação, preservação, difusão e expansão das heranças culturais das duas regiōes. Há, portanto, um equilíbrio entre universalidade de valores e particularidades culturais.

O ineditismo da pretendida associação estratégica nas relações internacionais também está no fato de que ela contempla o combate à corrupção, ao racismo, à pobreza, às desigualdades sociais e às drogas, entre outros problemas.

A "Associação Estratégica" entre as duas regiōes, inaugurada pela Cúpula do Rio, pode ser vista como uma tentativa de colocar em prática um conceito cosmopolita de justiça internacional, segundo o qual as pessoas de diversas cidadanias têm obrigaçôes individuais umas para com as outras, de forma semelhante aos cidadãos de um mesmo Estado.

A solidariedade cosmopolita, no entanto, não é apenas uma questão moral. Tornou-se hoje também uma necessidade prática, já que problemas que afetam todo o planeta, como a desigualdade, a pobreza, a deterioração do meio ambiente, a corrupção, as doenças contagiosas e o tráfico de drogas, entre outros, só podem ser efetivamente resolvidos através de açôes coordenadas no âmbito da comunidade internacional.

Por outro lado, "ações globais para problemas globais" precisam ser precedidas por um novo instrumental teórico, já que os conceitos da ciência política, inclusive os da teoria realista das relaçóes internacionais, foram moldados a partir da existência do Estado como Estado-nação, conceito que hoje parece obsoleto para lidar com os desafios postos pelo processo de globalização.

A "Associação Estratégica", ao contrário, seria um desses novos conceitos que nos permitiria lidar com situações globais através de ações concertadas no plano do sistema internacional. Embora as Declarações do Rio, Madri e Guadalajara respeitem princípios ligados ao Estado-nacional, como soberania, autodeterminação e não-intervenção, elas também apresentam objetivos que, para serem alcançados, exigirão uma reinterpretação daqueles conceitos no sentido de uma compreensão dos processos de integração regional como uma forma de compartilhar soberania e todas as demais responsabilidades dali decorrentes.

Os objetivos da Cúpula do Rio foram confirmados na reunião de Madri, em 2002, com uma declaração política de 33 compromissos, entre eles o do combate ao terrorismo, tema que ganhou novo relevo depois do atentado às Torres Gêmeas de Nova York, em 11 de setembro de 2001.

No âmbito econômico, é importante lembrar que a Cúpula de Madri ocorreu após o início das negociações da Rodada de Doha, da Organização Mundial do Comércio (OMC). Refletindo o otimismo que cercou a abertura dessa nova rodada, a declaração de Madri destacou as boas perspectivas de uma conclusão das negociações do Acordo de Associação entre a UE e o Chile e o avanço das negociações entre a União Européia e o Mercosul. O documento também apoiava 
as novas iniciativas de negociações de acordos políticos e de cooperação entre a UE e a América Central e entre a UE e a Comunidade Andina (CAN).

A partir de Madri as negociações entre a União Européia e a América Latina e o Caribe aconteceram numa relação de dependência dos resultados do ciclo de Doha da OMC. Por um lado, do ponto de vista da economia mundial como um todo, isto torna menos relevantes acordos como o que está sendo negociado entre a UE e o Mercosul, mas, por outro, também diminui os entraves. Uma redução dos subsídios da Política Agrícola Européia (PAC) no âmbito da OMC, por exemplo, facilitaria consideravelmente as negociações entre a União Européia e o Mercosul, que têm como um de seus principais obstáculos justamente a questão dos preços agrícolas europeus, distorcidos pelas diversas formas de proteção que recebem dos cofres comunitários.

Apesar de a Declaração de Madri ter contemplado as novas preocupações da comunidade internacional como o terrorismo e o início de uma nova rodada multilateral de liberalização comercial, ela basicamente reafirmou os compromissos de uma "Associação Estratégica", apresentados primeiramente pela Declaração do Rio. Essa necessidade de reiterar o compromisso evidencia que as reuniōes ainda não se traduziram em ações concretas. A Diplomacia de Cúpulas continua se caracterizando por um alto nível declaratório e, ao mesmo tempo, apresenta um compromisso limitado na implementação dos acordos alcançados. Uma das maneiras de contornar problemas desta natureza seria, provavelmente, a criação de uma estrutura executiva bi-regional das Cúpulas, com autoridade para cobrar a implementação das declaraçõos aprovadas.

A Cúpula de Guadalajara também reafirmou os objetivos das reunióes anteriores, mas adaptando-os ao novo contexto do pós-guerra no Iraque. A decisão dos Estados Unidos e do Reino Unido de intervir militarmente no Iraque, sem o aval do Conselho de Segurança, colocou em xeque a credibilidade das Nações Unidas. Tornou-se então premente que, em defesa do respeito ao direito internacional, garantido pelas Naçóes Unidas, Guadalajara se pronunciasse contra aquela ação unilateral. Dentro desse contexto, a defesa de uma ordem internacional, baseada nos princípios do direito internacional, algo que já constituía o núcleo político da associação estratégica entre a UE e a América Latina e o Caribe desde 1999, ganhou ali novo relevo. Mais do que nunca, impôs-se em Guadalajara a necessidade de cuidar da reforma dos organismos internacionais para torná-los instrumentos eficazes de sustentação do multilateralismo.

Por outro lado, a crise econômica e política em vários países latinoamericanos e do Caribe tornou necessário, mais uma vez, retomar a agenda para o desenvolvimento. Assim, na $\mathrm{X}^{\mathrm{a}}$ Reunião de Altos Funcionários da Cúpula União Européia - América Latina e o Caribe, realizada na cidade de Vouliagmeni, na Grécia, durante o primeiro semestre de 2003, o então comissário das Relaçóes Exteriores da Comissão Européia, Chris Patten, propôs a coesão social como um tema de debate para a Cúpula de Guadalajara. 
A coesão social foi proposta pela União Européia e aceita pela América Latina e o Caribe na Declaração final do encontro. No entanto, não pode ser aceita, de forma acrítica, a adoção pela América Latina e o Caribe do modelo de coesão social europeu, como parece ter sido a intenção da Cúpula de Guadalajara. Mesmo porque a própria União Européia ainda não chegou a um consenso sobre a melhor forma de lidar com suas minorias. Tanto o multiculturalismo inglês e holandês, quanto a política de assimilação de outras culturas na França são ainda objeto de controvérsia em suas respectivas sociedades. Apesar dos laços históricos e culturais entre a Europa e a América Latina e o Caribe, estamos diante de duas realidades sociais muito distintas, com suas próprias particularidades culturais. A proximidade cultural deve, muito antes, servir para uma comparação positiva e para o benefício mútuo dos modelos de coesão social na Europa e na América Latina e no Caribe, e em nenhum caso para a imposição de um modelo sobre o outro, independente do fato de quem se mostre mais capaz e dinâmico.

Além da coesão social, as duas regiōes estabeleceram, na Declaração de Guadalajara, a meta de uma convergência econômica dentro de cada Estadonacional e no interior de cada região. No entanto, esse objetivo está, claramente, em contradição com a própria idéia de "Associação Estratégica" que aquele documento pretendeu reafirmar inicialmente. Isto porque, na "Associação Estratégica", a convergência econômica não pode estar limitada ao território nacional ou a uma região, mas deve abranger um espaço bi-regional.

\section{A Cúpula de Viena: expectativas e frustrações}

Como já comentado, a IV Cúpula União Européia - América Latina e o Caribe, celebrada em 11 e 12 de maio de 2006 em Viena, era aguardada com grande expectativa. Acreditava-se que ela poderia significar uma ruptura em relação às cúpulas anteriores e uma mudança qualitativa positiva. Em todos os encontros preparatórios, a Comissária das Relaçōes Exteriores da União Européia, Benita Ferrero-Waldner, mostrou seu otimismo com a Cúpula, perspectiva da qual ela não abriu mão mesmo após o fracasso da conferência.

Em nossa opinião, a Cúpula de Viena deixou muito a desejar, mas não pelos motivos enfatizados pela imprensa. Esta atribuiu o fracasso da reunião ao que classifica como uma crise no processo de integração europeu e latino-americano. $\mathrm{Na}$ Europa, a rejeição da França e da Holanda à Constituição Européia, em 2005, e o período de reflexão que se seguiu foram entendidos como momentos de paralisia da integração. No caso da América Latina, a crise estaria sendo causada, segundo os meios de comunicação, pelo esfacelamento da Comunidade Andina de Nações (CAN), cujos países integrantes vêm buscando fechar acordos bilaterais de livrecomércio com os Estados Unidos; o que provocou a recente saída da Venezuela em protesto àquele comportamento. Outro fato que dominou as discussões da Cúpula de Viena foi a estatização das multinacionais petrolíferas pelo governo 
boliviano no dia $1^{\circ}$ de maio, ou seja, 10 dias antes da reunião na Áustria. Entre as empresas atingidas está a Petrobras. O conflito de interesses nacionais da Bolívia e do Brasil levantou dúvidas, na imprensa, sobre a viabilidade de uma futura integração sul-americana.

Até poderíamos admitir o uso da palavra crise para nos referirmos a esses fatos ocorridos na Europa e na América do Sul, desde que entendêssemos a crise como uma etapa inevitável dos processos de integração.

$\mathrm{Na}$ Europa, ao longo das cinco décadas do processo de integração, as crises foram freqüentes e, por diversas vezes, decretou-se o fracasso do projeto comunitário europeu. Nessa medida, a "crise" da Constituição Européia deve ser colocada em suas devidas dimensões. Através dos Tratados de alargamento e aprofundamento - Maastrich, Amsterdã e Nice - entre 80 e $90 \%$ das normas previstas na Constituição já estão em vigor na UE. O não à Constituição, portanto, estaria relacionado a algumas normas polêmicas, que não chegam a representar entre 10 e $20 \%$ do texto constitucional. Não se trata aqui de reduzir a análise a porcentagens. É que, neste caso específico, a quantidade de leis comunitárias em vigor diz algo sobre a qualidade do processo de integração europeu.

Quanto à América do Sul, parece precipitado o diagnóstico de fracasso da integração ou, como muitas vezes apareceu nos meios de comunicação, de "fragmentação do Continente". A Venezuela deixou a Comunidade Andina, enfraquecida pela política de acordos bilaterais dos Estados Unidos com os países da área, para se associar ao Mercosul, que até agora - apesar de seus inúmeros problemas - é o processo de integração regional mais avançado da América do Sul. O deslocamento da Venezuela da CAN para o Mercosul representou, portanto, não um fracasso da integração, mas uma mudança de eixo na integração sul-americana, a partir de agora concentrada, sobretudo, no Mercado Comum do Sul.

Já a questão do gás boliviano poderia ter adquirido o caráter de uma crise no sentido de catástrofe da integração, caso o Itamaraty tivesse pautado sua atuação unicamente pelo interesse nacional. Se isto tivesse ocorrido, poderíamos falar hoje de uma crise da integração, com impossibilidade de qualquer diálogo entre o Brasil e a Bolívia. Ao contrário, a reação do governo brasileiro, equilibrando interesse nacional e regional e se aproximando da Bolívia, transformou o que poderia ser uma crise, que trava a história e impede qualquer saída, numa crise que é parte inerente ao processo de conquista do próprio destino pelas sociedades nacionais na região.

\section{A posição européia em relação à Cúpula}

Era de se esperar que a União Européia tivesse uma visão das dificuldades da integração latino-americana diferente daquela da imprensa, ou seja, que percebesse os problemas como "dores normais do parto". 
Afinal, foi assim que os europeus lidaram com os vários momentos de impasse, surgidos no próprio processo de integração européia. Na década de 80 , o europessimismo foi combatido por uma série de políticas destinadas a reformular e aprofundar a Comunidade Européia. O Relatório Cecchini, encomendado pela Comissão Européia, mostrou o quanto a Comunidade teria perdido, caso não tivesse realizado a integração. Em outros termos, aquele relatório apresentou os custos da não-integração européia. Cecchini desencadeou discussões sobre o projeto europeu que culminaram no Livro Branco de Jacques Delors e na preparação do Ato Único Europeu, o qual assentou as bases do que deveria ser a nova fase da integração, incluindo, a partir de então, a dimensão política. Percebe-se, portanto, que a "crise" ou euroceticismo da Comunidade Européia nos anos 80 levou à decisão de avançar mais na integração, um movimento de ir-para-a-frente.

Contudo, essa experiência com o seu próprio processo de integração não foi utilizada pela União Européia no momento de interpretar o que ocorria na América Latina e no Caribe. Em vez de entender a "crise" latino-americana como um percalço de um processo de aprendizagem, os europeus preferiram considerála uma crise de grandes proporções.

A União Européia também desconsiderou sua própria história ao argumentar, durante a Cúpula, que a "Associação Estratégica" não poderia progredir enquanto a América Latina não falasse com uma só voz, ou seja, enquanto não fosse um bloco consolidado com todos os seus problemas internos resolvidos. Ora, em diversos momentos de seu processo de integração, a UE sempre expandiu-se antes de resolver suas pendências anteriores. Em 2004, por exemplo, ela incorporou 10 novos países-membros sem que a discussão sobre a diretiva Bolkenstein, que trata da regulamentação do mercado de trabalho, estivesse concluída. O mesmo ocorreu com o Acordo de Schengen, que em 1985 suprimiu o controle de passaportes na fronteira dos Estados-membros signatários. $\mathrm{O}$ fato de apenas 13 dos 25 membros da União Européia participarem do Espaço Schengen nunca foi um empecilho ao avanço do processo de integração. Um exemplo ainda mais emblemático do que os dois anteriores é o da criação da Zona Euro, em 2002, quando 12 países substituíram suas moedas nacionais pelo euro. A rejeição da maioria dos Estadosmembros à nova moeda não impediu sua implementação pela UE nem sua posterior valorização no mercado financeiro internacional. No dia $1^{\circ}$ de janeiro de 2007, a Eslovênia tornou-se o décimo terceiro país a entrar na Zona Euro.

Nos processos de integração entre Estados, não há um primeiro momento - de resolução interna de problemas - seguido de um segundo momento - de abertura para o exterior. Muitas vezes, o aprofundamento e o alargamento ocorrem simultaneamente. O mesmo deveria ser possível no caso de uma integração entre dois blocos regionais. A União Européia e a América Latina e o Caribe podem prosseguir seus respectivos processos de integração e, ao mesmo tempo, avançar para uma "Associação Estratégica" entre si. Exigir a consolidação da integração latino-americana como pré-requisito para ampliar a cooperação bi-regional, ou 
seja, exigir do outro aquilo que se sabe que ele não pode dar no momento, parece uma atitude deliberada de estancar as negociações.

Em nossa avaliação, a Uniāo Européia deixou-se levar pelo discurso da crise da integração latino-americana, promovido pelos Estados Unidos. Estes não só apresentam o discurso da desintegração da América do Sul, como tentam transformar esse discurso em realidade, propondo acordos bilaterais com os países da região andina, mantendo o assinado com o Chile e tentando seduzir os dois parceiros menores do Mercosul: o Paraguai e o Uruguai.

A mesma estratégia de decretar a crise da integração ou a fragmentação de um bloco regional já havia sido utilizada pelos Estados Unidos em relação à própria Europa. É preciso lembrar que, em 2003, o secretário de Defesa norte-americano, Donald Rumsfeld, referiu-se a uma Velha Europa, formada pelos países contrários à invasão do Iraque, e a uma Nova Europa, alinhada a Washington. Ainda que tenham, de fato, ocorrido sérias divergências entre os países europeus sobre a invasão do Iraque, em nossa opinião, elas não foram suficientes para sustentar o argumento de um enfraquecimento da integração.

Percebemos, portanto, uma tendência da União Européia para endossar a política externa de Washington para a América Latina e para a própria Europa. Mas, ao assumir essa posição, a UE corre o risco de enfraquecer o seu próprio projeto de uma associação diferenciada com a América Latina e o Caribe. A política externa norte-americana visa dividir esses continentes com o objetivo de obter aliados para sua política externa unilateral. A associação estratégica propõe exatamente o oposto, isto é, uma atuação conjunta da Europa e da América Latina em favor de um multilateralismo que se contraponha ao unilateralismo hegemônico dos Estados Unidos.

\section{A Europa adotou a visão americana porque tem dificuldade para assumir a "Associação Estratégica"}

Acreditamos que a UE adotou a interpretação norte-americana da fragmentaçãoda América do Sul como um pretexto para encobrir a ausência de vontade política de seus líderes de promover, a curto prazo, uma verdadeira "Associação Estratégica", que abrangesse ao mesmo tempo todos os campos passíveis de serem integrados, quais sejam, o econômico, o político, o social e o cultural. Uma associação deste tipo poderia ter um alto custo para a União Européia, pois implicaria um compromisso com a justiça distributiva e a solidariedade num espaço bi-regional.

Os acordos assinados nas quatro cúpulas, sobre cooperação nas áreas de infra-estrutura, energia, transporte, telecomunicaçōes, pesquisa, combate à pobreza e à desigualdade, migração, criação de emprego e educação, só poderão ser efetivamente executados se forem acompanhados por expressivos investimentos, principalmente por parte da União Européia. 
Apesar das evidências de que a Cúpula de Viena não foi uma reunião para destravar a associação estratégica, que permanece assim diante dos mesmos desafios, a Comissária de Relaçōes Exteriores da UE, Benita Ferrero-Waldner, apontou algumas inovaçóes. Ela destacou o lançamento das negociações para um acordo de associação (incluindo uma área de livre-comércio) com a América Central, a proposta de estabelecer uma Assembléia Parlamentar UE-ALC e a assinatura do Memorando de Entendimento entre a Comissão Européia e a Secretaria-Geral Iberoamericana para Processo de Cúpulas.

Concordamos parcialmente com os dois últimos avanços apontados por Ferrero-Waldner. A parceria entre Parlamentos é uma condição necessária, mas não suficiente, para romper com o caráter meramente declaratório da Diplomacia de Cúpulas e implementar os temas constantes dos documentos.

O diálogo bem-sucedido entre o Parlamento europeu e o Parlamento chileno nos permite algum grau de otimismo em relação à Assembléia Parlamentar UE-ALC e ao entendimento entre Comissão Européia e Secretaria-Geral Iberoamericana. Em 2003, os eurodeputados, sobretudo os verdes, contestaram o acordo comercial entre a União Européia e o Chile devido às conseqüências negativas, tanto sociais quanto ambientais, decorrentes da produção de celulose. O episódio mostrou que os Parlamentos poderiam ter papel fundamental na consideração de outros aspectos da integração, que não os meramente econômicos. Para os eurodeputados, o respeito pelas normas sociais e ambientais não poderia ser flexibilizado para beneficiar o intercâmbio comercial. Podemos dizer, portanto, que as instituições parlamentares podem contribuir para fazer avançar a associação estratégica, na medida em que ampliam a discussão para além das questōes econômicas.

Mas não são apenas essas instâncias executiva (Comissão-SEGIB) e de diálogo inter-institucional (Assembléia Parlamentar) que podem contribuir para ir além do nível declaratório das cúpulas e implementar os acordos. Muitas vezes, os resultados de outros fóruns e outras negociaçōes em curso também servem para fazer avançar as discussões entre a União Européia e a América Latina e o Caribe.

As Cúpulas Ibero-americanas entre chefes de Estado e de Governo, iniciadas em 1991 por iniciativa de Portugal e Espanha, foram precursoras das Cúpulas UE-ALC, que até hoje são influenciadas pelos seus resultados e discussões. A Secretaria-Geral Iberoamericana (SEGIB), por exemplo, é uma criação da XV Cúpula Ibero-americana de chefes de Estado e de Governo, realizada na cidade de Salamanca nos dias 14 e 15 de outubro de 2005.

A XVI Cúpula Iberoamericana, ocorrida entre os dias 3 e 5 de novembro de 2006 em Montevidéu, Uruguai, tratou de um tema também caro às Cúpulas UEALC: "Migração e Desenvolvimento". Em Montevidéu, criticou-se a tendência atual dos países desenvolvidos de frear o fluxo migratório com medidas radicais; uma posição incompatível com a proposta de solidariedade cosmopolita implícita no conceito de Associação Estratégica da Cúpula UE-ALC. 
A interdependência entre os diversos fóruns de negociação pode ainda ser exemplificada pela mais recente reunião UE-Mercosul, realizada nos dias 6 e 7 de novembro de 2006, no Rio de Janeiro. As conversas estavam suspensas desde o final de 2004, por conta do desacordo em torno das ofertas, pois a União Européia exigia maior abertura em serviços e investimentos e o Mercosul queria o fim dos subsídios agrícolas na União Européia.

Essa reunião teve resultados positivos e negativos. Seus méritos foram retomar as conversas que corriam o risco de permanecerem estancadas, à espera de uma definição da Rodada de Doha da OMC, e marcar outro encontro para daqui a três meses. Nesse sentido, ela pode ser vista como um mecanismo entrecúpulas, que promove o diálogo entre a UE e o Mercosul. No entanto, essas conversas seguem concentradas nas questôes econômicas, desconsiderando os aspectos político e social da integração. Em suma, trata-se de um mecanismo entre cúpulas exclusivamente econômico.

\section{Conclusão}

A maior institucionalização das cúpulas e o aproveitamento dos resultados de outras reuniōes, como vimos, não garantem uma associação estratégica. Esses fóruns de diálogo terão de ser acompanhados pela vontade política dos líderes da União Européia e da América Latina, que só poderão se comprometer com uma parceria bi-regional ambiciosa se conseguirem se livrar do discurso da "fragmentação da América do Sul", o que implica em assumir as crises como parte integrante e normal dos processos de integração.

Recebido em 27 de fevereiro de 2007 Aprovado em 10 de junho de 2007

\section{Referências}

ARCAYA, Óscar Godoy. Parlamento, presidencialismo y democracia protegida. Acesso em: 10.8.06.

Disponível em: www.scielo.cl/scielo.php?pid=S0718-090X2003000200002\&script=sci_ arttext

ANUÁRIO BRASIL - EUROPA 2001. Resumo das rodadas de negociações EU - Mercosul realizadas em 2001. In: Anuário Brasil - Europa 2001, Rio de Janeiro: KAS, 2001, p. $175-180$.

ANUÁRIO BRASIL - EUROPA 2002. Resumo das rodadas de negociações EU - Mercosul realizadas em 2002. In: Anuário Brasil - Europa 2002, Rio de Janeiro: KAS, 2002, p. 281-285.

ANUÁRIO BRASIL - EUROPA 2004. Resumo das rodadas de negociações EU - Mercosul realizadas em 2004. In: Anuário Brasil - Europa 2004, Rio de Janeiro: KAS, 2002, p. $225-228$. 
ARELA. Anuário de las Relaciones Europeo - Latinoamericanas. Madrid: IRELA, 1994, 407 p.

AZNAR, J.P. Acordo de Associação EU - Mercosul: posição das negociações comerciais. In: Anuário Brasil - Europa 2002, Rio de Janeiro: KAS, 2002, p. 25 - 36.

BAUMAN, R. A Cimeira de Madri: uma avaliação econômica das expectativas para a agenda das relaçōes bi-regionais. In: Anuário Brasil Europa 2002. Rio de Janeiro: KAS, 2002, p. $13-24$.

BAUMAN, Z. Globalização. As conseqüências humanas. Rio de Janeiro: Jorge Zahar Editor, $1999,145 \mathrm{p}$.

BEITZ, Ch. Political Theory and International Relations. New Jersey: Princeton University Press, 1999, 225 p.

CASANUEVA, H. Prólogo. In: Acuerdos Union Europea / América Latina. El diseño de la Asociación Estratégica Bi-regional, Santiago: CELARE, 2005, p. 9-18.

CELARE. América Latina - Unión Europea. Documentación de Base 2001. Santiago : CELARE, 2002, 291 p.

CELARE. II Cumbre Unión Europea - América Latina y el Caribe. Reflexiones y Proyecciones tras Madrid 2002. Santiago: CELARE, 2002, 254 p.

CELARE. América Latina - Unión Europea. Documentación de Base 2002. Santiago : CELARE, 2003, 343 p.

DAUSTER, J. Mercosul - União Européia : rumo à associação inter-regional. In: Política Externa, São Paulo: Paz e Terra, vol. 4, no 4, 1996, p. 35-48.

DUPRET, Paul-Emile.....Dans le sillage de Washington. Risal - Réseau d'information et de solidarité avec l'Amérique latine. [http://risal.collectifs.net/imprimer.php3?id_article=509] Disponibilidade: 19.10.06.

FERRERO-WALDNER, B. Associação estratégica entre a UE e a ALC. Cúpula de Viena contribuiu significativamente para o início efetivo de sua consolidação. Gazeta Mercantil. 25.6.2006, p. A-10.

GRABENDORFF, W., SEIDMANN, R. (org.). Relations between the European Union and Latin AmericaI.Baden-Baden: Nomos, 2004, 443 p.

JANK, M. e outros. Negociações sobre agricultura UE- Mercosul. In: Anuário Brasil - Europa 2004, Rio de Janeiro: KSA, 2004, p. 127-164

LEITE, P. Negociações comerciais Mercosul - União Européia. In: Anuário Brasil - Europa 2004, Rio de Janeiro: KAS, 2004, p. 101-126.

MACHINEA, J. L. La Construcción de un projecto latinoamericano: integración y cohesión social. Santiago: CELARE, 2002, 245 p.

MAIHOLD, Günther. La Cumbre de Viena entre América Latina/Caribe y la UE: el éxito relativo de un encuentro de bajas expectativas (ARI). Real Instituto Elcano de Estudios Internacionales y Estratégicos. [http:www.realinstitutoelcano.org/analisis/imprimir/ 978imp.asp] Disponibilidade: 30. 08.06.

MARCONINI, M., FLÔRES, R. (org.). Acordo Mercosul - Uniāo Européia. Além da agricultura. Brasília: CEBRI, 2003, 268 p.

MARTÍN, Araceli Mangas. La Constitución Europea. Madrid: Iustel, 2005, 239 p. 
NAVARRO, Luis Hernández. Le sommet de Guadalajara. Risal - Réseau d'information et de solidarité avec l'Amérique latine. [http://risal.collectifs.net/imprimer.php3?id_article=977] Disponibilidade: 19.10.06.

RÊGO, Elba Cristina Lima. Do Gatt à OMC: o que mudou, como funciona e para onde caminha o sistema multilateral de Comércio. [www.bndes.gov.br/conhecimento/revista/gatt.pdf] Disponibilidade: 12.10 .06 .

SANTOS, Th. As relações Brasil - Europa em transição. In: Anuário Brasil - Europa 2000, Rio de Janeiro: KAS, 2000, p. 191-200.

TREIN, F., As relaçōes Brasil - União Européia: ano 2000. In: Anuário Brasil - Europa, Rio de Janeiro: KAS, 2000, p. 169-190

VEGA, R. Grandes tendências das relaçôes entre a União Européia e o Mercosul. In: Anuário Brasil - Europa 2000, Rio de Janeiro: KAS, 2000, p. 121-148.

VIZENTINI, P.G.F. A cooperação União Européia - Mercosul face à Alca: dificuldade e possibilidades. In: Anuário Brasil - Europa 2000, Rio de Janeiro: KAS, 2000, p. 149-168.

\section{Documentação}

DECLARAÇÃO POLÍTICA: Compromisso de Madri (Madri, 17 de maio de 2002) http://europa.eu.int/comm, Reproduzido in: Anuário Brasil - Europa 2002, Rio de Janeiro: KAS, 2002

Declaração do Rio de Janeiro: http://ec.europa.eu/europeaid/projects/alis/alis3_for/ declaration_of_rio_pt.pdf

Declaração de Guadalajara: http://ec.europa.eu/wiold/lac-guadal/declar/01_del\%20polit_ final_pt.pdf, Disponibilidade: 15.05.06.

Declaração de Viena: http://noticias.uol.com.br/ultnot/afp/2006/05/12/ult34u154379. jhtm, Disponibilidade: 15.05.06.

Declaração de Salamanca: XV Conferência Ibero-Americana de Chefes de Estado e de Governo. http://www.oeibrpt.org/xvcumbre.htm, Disponibilidade: 10.10.05.

Eurolat -Carta Informativa - Resultados da "IV Cumbre Unión Europea/América Latina y El Caribe. Número 70, 26 de mayo de 2006.

Eurolat -Carta Informativa - Resolución del Parlamento Europeo sobre una Asociación reforzada entre la Unión Europea y América Latina. Número 69, 30 de abril de 2006.

Hacia una Cumbre Nueva. Seminario "De Guadalajara a Viena: Orientaciones para la IV Cumbre UE/ALC", organizado por CELARE, CEPAL y las universidades San Pablo CEU, de España, y Miguel de Cervantes, de Chile, en Santiago de Chile, el 18 y 19 de julio de 2005 (paper).

\section{Resumo}

No artigo se realiza um exame crítico das relações entre a União Européia, América Latina e Caribe. O objetivo é explicitar a "associação estratégica" entre aqueles parceiros, proposta no Rio de Janeiro em 1999 e reiterada pela Cúpula de Viena em 2006. O texto pretende mostrar ainda por que estas reuniões não conseguiram uma aproximação efetiva. 


\section{Abstract}

A critical analysis of the relations between the European Union, Latin America and Caribbean. This article aims to explicit the "strategic association" between those partners, proposed in Rio de Janeiro, in 1999, and reiterated by the Vienna Summit in 2006. The text also intends to demonstrate why these meetings failed to foster an effective approximation.

Palavras-chave: Associação Estratégica, União Européia, América Latina, Caribe, Mercosul, Integração, Relações Birregionais e Justiça Distributiva.

Key words: Strategic association, European Union, Latin America, Caribbean, Mercosul, Integration, Bi-regional Relations and Distributive Justice. 